\title{
Down's Syndrome- A Disease Caused By Genetic Alteration
}

\author{
Vijayendranath Nayak $S^{1 *}$, Raghavendra Kini' ${ }^{2}$, Prasanna Kumar Rao ${ }^{3}$, Ashish S Shetty ${ }^{4}$ Nidhin Kurian $^{4}$ and \\ Soumya Shetty
}

${ }^{1}$ Postgraduate, Department of Oral Medicine and Radiology, A J Institute of Dental Sciences, India

${ }^{2}$ Professor and Head, Department of Oral Medicine and Radiology, A J Institute of Dental Sciences, India

${ }^{3}$ Professor Department of Oral Medicine and Radiology, A J Institute of Dental Sciences, India

${ }^{4}$ Postgraduate, Department of Pedodontics, A J Institute of Dental Sciences, India

${ }^{5}$ Professor and Head, Department of Pedodontics, A J Institute of Dental Sciences, India

Received: 䟧 April 16, 2018; Published: 㘹 May 07, 2018

*Corresponding author: Vijayendranath Nayak S, Postgraduate, Department of Oral Medicine and Radiology, A.J .Institute of Dental Sciences, Kuntikana, Mangaluru, Karnataka, India

\begin{abstract}
Down's syndrome is the most common syndrome, medical professional encounters in day to day practice. It is a genetic disorder with a typical face profile and few classical intraoral features. Herein we report case and review on Down's syndrome with facial features.
\end{abstract}

Keywords: Down's Syndrome; Trisomy; Chromosome; Oral Manifestation

\section{Introduction}

Down syndrome is one of the commonest disorders with huge medical and social cost. DS is associated with number of phenotypes including congenital heart defects, leukemia, Alzheimer's disease, Hirsch sprung disease etc. [1]. Down syndrome is a prevalent genetic disorder in intellectual disability in India. Its prevalence in tribal population is not known [2]. Down syndrome is one of the leading genetic causes of intellectual disability in the world. DS alone accounts $15-20 \%$ of ID population across the world $[3,4]$.

\section{Case Report}

An 8 year old male patient came to the department of oral medicine and radiology for routine dental check-up. Extra oral examination revealed characteristic facial profile with increased inter canthal distance (Figure 1). Intraoral examination revealed Gingiva was soft with deposits on the teeth, High arched palate, with depressed nasal bridge was seen (Figure 2). Macro glossia was also seen .Correlating the intraoral and extra oral findings a Provisional diagnosis of Down's syndrome/ Trisomy 21 was given. Patient was referred to the respective departments of pedodontics

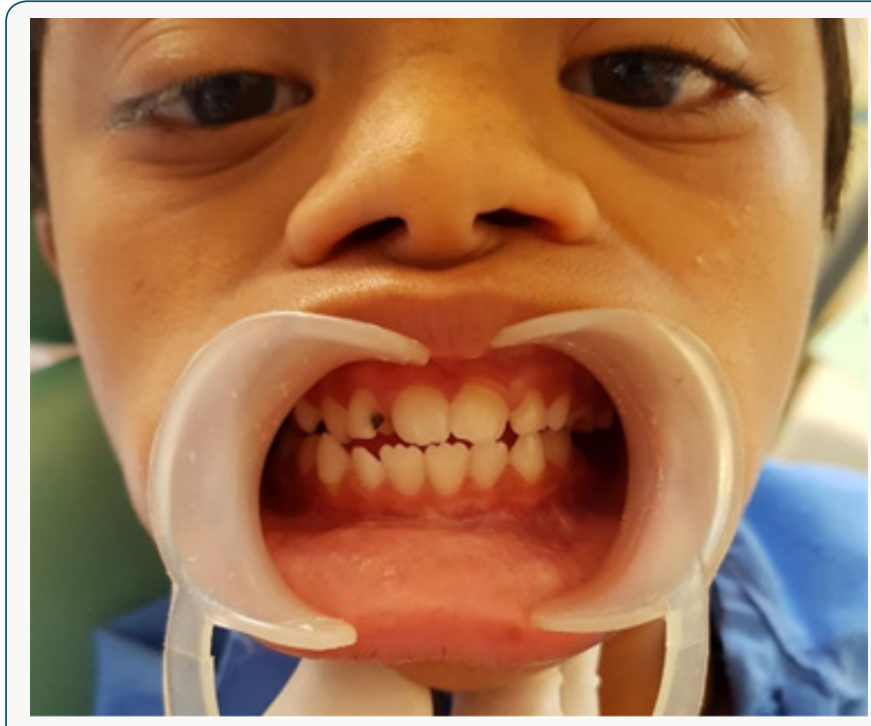

Figure 1: Extra oral features showing increased inter canthal distance and depressed nasal bridge. for restoration of decayed teeth.] 


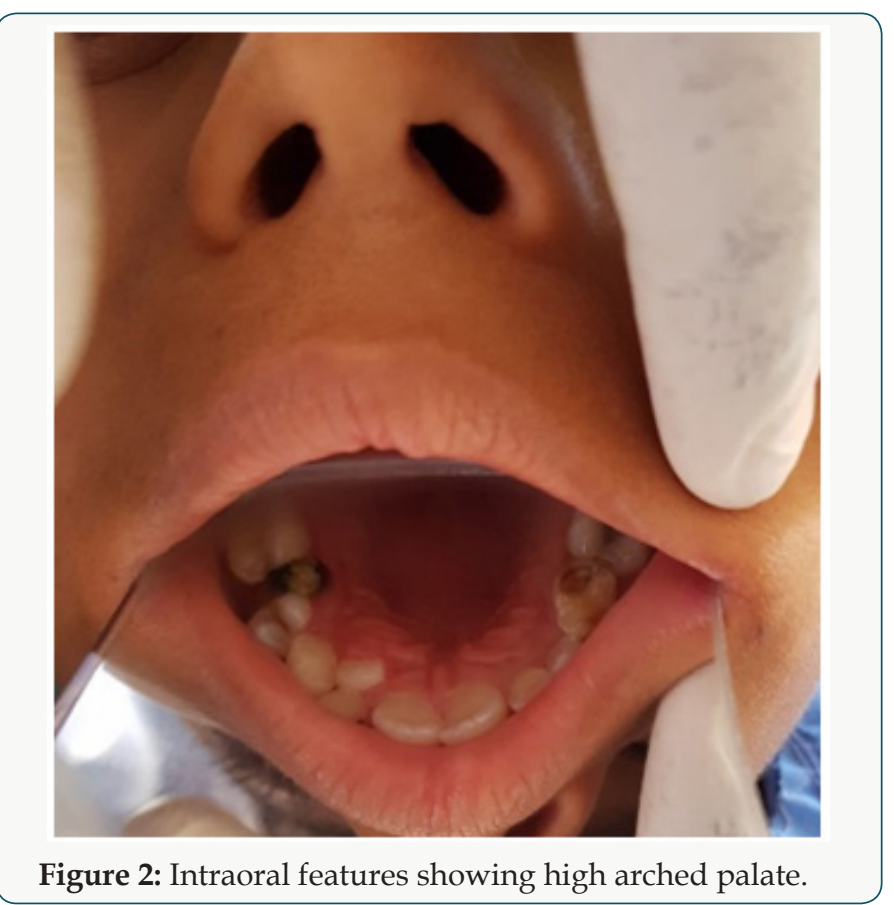

\section{Discussion}

Down syndrome is one of the most leading causes of intellectual disability and millions of these patients face various health issues including learning and memory, congenital heart diseases, Alzheimer's diseases, leukemia, cancers and Hirsch rung disease. The incidence of trisomy is influenced by maternal age and differs in population [5,6]. Facial findings in the patients can be characterised into extra oral and intraoral features (Table 1) [7]. Parents of children with Down's syndrome should be aware of these possible conditions so they can be diagnosed and treated quickly and appropriately. According to Asim A et al. A Down's syndrome child should have regular check-up from various consultants. These include:

Table 1:

Extra oral and intraoral finding in a down's syndrome patient

\begin{tabular}{|l|c|}
\hline \multirow{5}{*}{ Extra oral findings } & Microcephaly \\
Flattened face \\
Small nose \\
Depressed nasal Bridge \\
Wide neck \\
Almond shaped eyes \\
Dysplastic small ears \\
Hypertelorism \\
\hline \multirow{5}{*}{ Intraoral findings } & $\begin{array}{c}\text { Hard tissue: Dental caries, } \\
\text { Microdontia, Anodontia, } \\
\text { Hypodontia, High arched palate, } \\
\text { Narrow palatal arch. }\end{array}$ \\
\cline { 2 - 2 } & $\begin{array}{c}\text { Soft tissues: Aphthous ulcers, Bald } \\
\text { tongue, Fissured tongue, Gingivitis, } \\
\text { Periodontitis, Oral candidiasis, } \\
\text { Halitosis. }\end{array}$ \\
\hline
\end{tabular}

a) Clinical geneticist - Referral to a genetic counselling program is highly desirable.

b) Developmental paediatrician.

c) Cardiologist - Early cardiologic evaluation is crucial for diagnosing and treating congenital heart defects, which occur in as many as $60 \%$ of these patients.

d) Paediatric pneumonologist -Recurrent respiratory tract infections are common in patients with DS.

e) Ophthalmologist.

f) Neurologist/Neurosurgeon - As many as $10 \%$ of patients with DS have epilepsy; therefore, neurologic evaluation may be needed.

g) Orthopaedic specialist.

h) Child psychiatrist - A child psychiatrist should lead liaison interventions, family therapies, and psychometric evaluations.

i) Physical and occupational therapist.

j) Speech-language pathologist.

k) Audiologist.

l) Paediatric dentist.

Hackshaw AK et al in their study, proposed a new screening method in which measurements obtained during 1st and 2nd trimester are integrated to provide the risk status of having pregnancy with DS. Moderate to severe intellectual disability occur as a constant feature, with IQ's ranging from 20 to 85 [8]. Kennard in his review stated that there are a number of ultrasound markers in Down's syndrome which includes nuchal fold thickness, cardiac abnormalities, duodenal atresia, femur length \& pyelectasis [9]. The signs and symptoms of Down's syndrome are characterised by neotenization of brain and bodies. Management strategies such as early childhood intervention, screening from common problems, medical treatment when indicated, a conductive family environment and vocational training can improve the overall development of children with Down's syndrome [10].

\section{Conclusion}

Genetics have always have played a major role in physical and mental being of an individual. Downs patients being mentally and medically weak, best care needs to be taken with adequate precautions.

\section{References}

1. Asim A, Kumar, A, Muthuswamy S, Jain S, Agarwal S (2015) Down syndrome: An insight of the disease. J Biomed Sci 22(1): 41.

2. Lakhan R, Kishore TM (2016) Down syndrome in tribal population in India: A field observation. J Neurosci Rural Pract 7(1): 40-43.

3. Patterson D, Costa AC (2005) Down syndrome and genetics-A case of linked histories. Nat Rev Genet 6: 137-147. 
4. Understanding Intellectual Disability and Health. Down syndrome.

5. Canfield MA, Honein MA, Yuskiv N, Xing J, Mai CT, et al. (2006) National estimates and race/ethnic-specific variation of selected birth defects in the United States. Birth Defects Res A Clin Mol Teratol 76(11): 747-756.

6. Murthy SK, Malhotra AK, Mani S, Shara ME, Al Rowaished EE, et al. (2007) Incidence of Down syndrome in Dubai. Med Princ Pract 16: 25-28.

7. Nayak V, Kini R, Rao PK (2016) Oral manifestation of trisomy 21- a report and review. Jpmr 2(6): 142-143.
8. Zigman WB (2013) A typical aging in Down's syndrome. Dev Disbil Res Rev 18(1): 51-67.

9. Kennard A, Wald NJ, Mc Guire A (1997) Antenatal screening for Down's syndrome. Journal of Medical Screening 4(4): 181-246.

10. Harshithaa N, Maragathavalli G (2014) Case Report Down's syndrome 13(1): 03-04

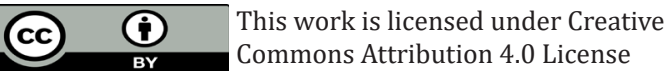

To Submit Your Article Click Here:

Submit Article

DOI: 10.32474/MADOHC.2018.02.000131

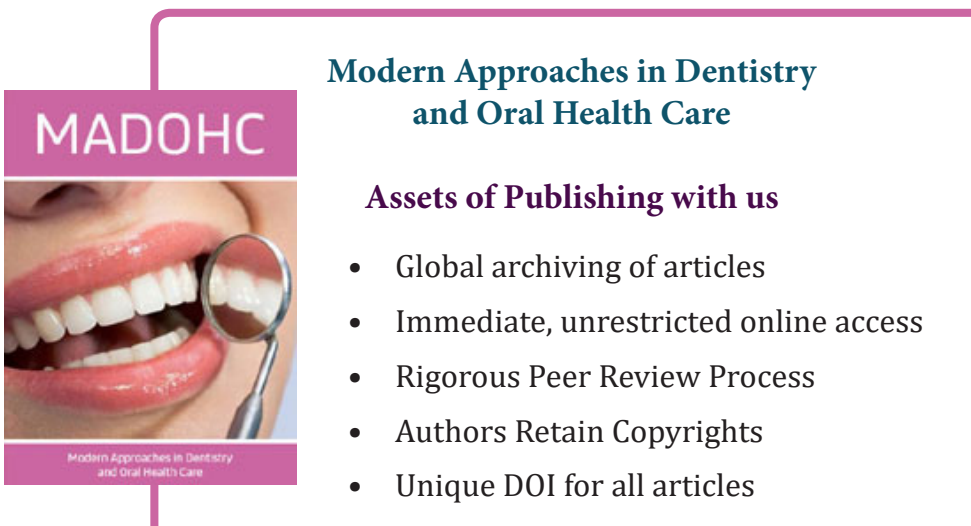

